\title{
Removal of Nitrate and Nitrite Anions from Wastewater Using Activated Carbon Derived from Rice Straw
}

\author{
Hassan A Hanafi ${ }^{1,2 *}$ and Sami M Abdel Azeema ${ }^{2,3}$ \\ ${ }^{1}$ Cyclotron Project, Nuclear Research Centre, Atomic Energy Authority PN, 13759, Cairo, Egypt \\ ${ }^{2}$ College of Science and Humanities, Al-Quwayiyah-Shaqra University-KSA, Saudi Arabia \\ ${ }^{3}$ Chemistry Department, Faculty of Science, Fayoum University, Fayoum, Egypt
}

\begin{abstract}
Rice straw (RS) has been activated using $\mathrm{Na}_{2} \mathrm{CO}_{3}$. Activated carbon samples (ARSC) were characterized using $\mathrm{N}_{2}-$ adsorption, elemental analysis, surface fractional dimension and pore volume to support the adsorption of nitrate and nitrite ions. The effects of various parameters such as solution $\mathrm{pH}$, adsorbent concentration, contact time, temperature and initial nitrate and nitrite concentrations were examined. Various kinetics models including the Pseudo-first-order, Pseudo-second-order and intra particle diffusion models have been applied to the experimental data to predict the adsorption mechanism. The thermodynamics constants of the adsorption process, viz. $\Delta \mathrm{H}^{\circ}, \Delta \mathrm{G}^{\circ}$ and $\Delta \mathrm{S}^{\circ}$ were evaluated. The results showed that the adsorption of nitrate and nitrite ions onto activated carbon was exothermic and non-spontaneous. The adsorption data followed second-order kinetics supporting that chemisorption process was involved. The obtained results show that ARSC can be used as an effective and natural low-cost adsorbent for the removal of nitrate and nitrite anions from wastewater.
\end{abstract}

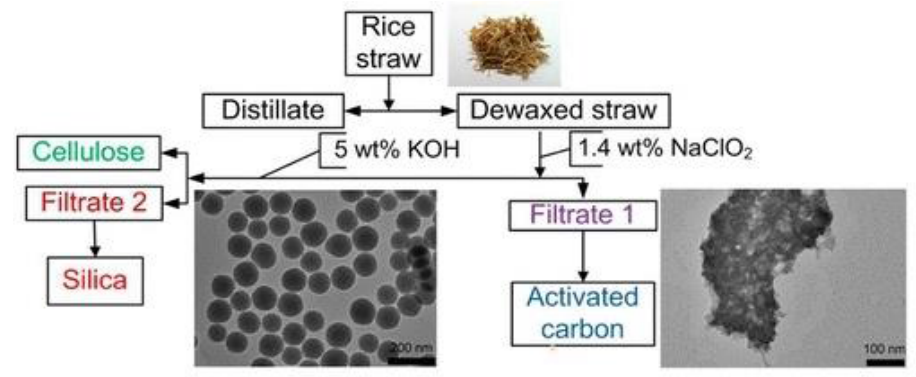

Schematic diagram for preparation of activated carbon produces from rice straw.

Keywords: Activated carbon; Rice straw; Adsorption; Nitrate; Nitrite; Wastewater

\section{Introduction}

Nitrogen $(\mathrm{N})$ is an essential element for all living matter. Nitrogen exists in different oxidation states such as $\mathrm{NO}_{3}^{-}(+5), \mathrm{NO}_{2}^{-}(+3)$ and ammonium $\mathrm{NH}_{4}^{+}(-3)$. Among these, $\mathrm{NO}_{3}^{-}, \mathrm{NO}_{2}^{-}$and $\mathrm{NH}_{4}^{+}(-3)$ are of more concern because they are soluble in water causing toxicity to human health [1]. Contamination of groundwater and surface water by nitrate coming from non-point sources such as agricultural fertilization has become a growing environmental problem so it becoming a common concern of both industrial and developing countries [2]. Nitrate contaminations increasingly occurs due to the widespread use of fertilizers containing nitrate and owing to poorly treated or untreated human and animal wastes. Nitrate is a by-product of many industrial processes, including paper and explosives manufacturing and the production of nitro-organic and pharmaceutical compounds [3]. The increasing nitrate concentration in the groundwater causes a serious health risk, responsible for the blue baby syndrome and a precursor to carcinogenic nitrosamines [4]. For these reasons, the European Community limits nitrate and nitrite concentrations in drinking water [5].

Nitrite and nitrate are also a form of non-radioactive waste present in more radioactive waste; nitric acid is employed in processing extremely toxic radioactive elements such as uranium, plutonium and americium during the production of nuclear weapons and nuclear fuel. However, if nitrate is also present in high concentrations, it may interfere with the formation of stable cement matrix, making it difficult to use this process for the long-term disposal of various metal processing wastes [6]. Therefore, removal of nitrate and nitrite is of significant importance from the health and environmental point of view.

Conventional methods for removing nitrate and nitrite anions from wastewater include reverse osmosis, ion exchange, combined membrane bioreactor/powdered activated carbon adsorption, the biofilm-electrode reactor (BER) and the BER/adsorption process [7]. Most of these methods suffer from some drawback, such as the high capital or high operational cost or the disposal of the resulting sludge $[7,8]$.

Recently, numerous low-cost alternative adsorbents have been examined for the removal of nitrate and nitrite anions from wastewater [9-13].

*Corresponding author: Hassan A. Hanafi, College of Science and Humanities Al-Quwayiyah-Shaqra University-KSA, Saudi Arabia, Tel: 966116224481; E-mail: white_heart200014@yahoo.com

Received October 29, 2015; Accepted December 31, 2015; Published January 04, 2016

Citation: Hanafi HA, Azeema SMA (2016) Removal of Nitrate and Nitrite Anions from Wastewater Using Activated Carbon Derived from Rice Straw. J Environ Anal Toxicol 6: 346. doi:10.4172/2161-0525.1000346

Copyright: (c) 2016 Hanafi HA, et al. This is an open-access article distributed under the terms of the Creative Commons Attribution License, which permits unrestricted use, distribution, and reproduction in any medium, provided the original author and source are credited. 
The present work was directed at improving the capability of ARSC for removing nitrate and nitrite ions from wastewater. To achieve this goal, the following studies were undertaken: (a) preparation and characterization of ARSC, (b) establishment of the conditions under which the maximum adsorption of nitrate and nitrite ions onto ARSC occur using column technique, and (c) evaluation of the kinetic and thermodynamic parameters for nitrate and nitrite ions adsorption onto ARSC.

\section{Experimental}

\section{Materials and methods}

Materials: Rice straw (RS) is a distinguished type of precursor in comparison to other agricultural by-products. It obtained from agricultural regions in Sharqia-Egypt.

Preparation of activated carbons: Half a kilogram of dried rice straw is fed into the fluidity bed reactor, described elsewhere [8], at a heating rate $50^{\circ} \mathrm{C}$ per $15 \mathrm{~min}$ in the presence of $\mathrm{N}_{2}$ flow $(200 \mathrm{~mL}$ $\left.\mathrm{min}^{-1}\right)$. Assess of the reactor was $5 \mathrm{~mL} \mathrm{~min}{ }^{-1}$ when the furnace reached $350^{\circ} \mathrm{C}$ and the heating continued up to a final temperature of $650^{\circ} \mathrm{C}$. The hold time was $1 \mathrm{~h}$ and the furnace was stopped. Carbon given the abbreviation. $1.0 \mathrm{~g}$ of carbon samples were mixed with $25 \mathrm{~mL}$ of 0.1 mol L-1 $\mathrm{Na}_{2} \mathrm{CO}_{3}$ solution for $72 \mathrm{~h}$ at $50^{\circ} \mathrm{C}$, washed with water and stored in stopper bottle.

Samples characterization: Samples were characterized by using nitrogen adsorption at $[77 \mathrm{~K}]$ using (Quantachrome Instruments, Model Nova1000e series, USA). The samples were outgased at $250^{\circ} \mathrm{C}$ under $\mathrm{N}_{2}$ flow for $16 \mathrm{~h}$. The $\mathrm{pH}$ of the samples was adjusted [9].

Adsorption studies: Sample Selection: A fixed amount of both non-oxidized and oxidized dry adsorbent $(0.1 \mathrm{~g})$ and $25 \mathrm{~mL}$ aliquots of the stock solution of initial concentration $\mathrm{Co}=25 \mathrm{mgL}^{-1}$, for each solute were shaken for $24 \mathrm{~h}$. Each mixture was filtered and the residual, nitrate and nitrite content in the solution was determined for knowing the effect of equilibrium time.

The $\mathrm{pH}$ of the solutions was adapted from 2 to 11 by diluting $\mathrm{NaOH}$ or $\mathrm{HCl}$ solutions. We used $20 \mathrm{~mL}$ of the $\mathrm{pH}$ adjusted solution and $30 \mathrm{mg}$ adsorbent in batch experiments conducted at the determined equilibrium time. The $\mathrm{pH}$ value provides the maximum anion removal was determined.

Experiments were carried out by taking $20 \mathrm{ml}$ of a nitrate-ionsspiked aqueous solution of an initial concentration of $50 \mathrm{mg} \mathrm{L}^{-1} \mathrm{NO}_{3}^{-}$ and carbon dose of $200 \mathrm{mg}$ in the presence of different quantities of $\mathrm{Ca}\left(\mathrm{HCO}_{3}\right)_{2}$ in the range of $0-400 \mathrm{mg} \mathrm{L}^{-1}$. Effect of shaking time was done at $24 \mathrm{~h}$ at $25^{\circ} \mathrm{C}, 45$, and $55^{\circ} \mathrm{C}$.

\section{Methods}

Metrohm 690 ion chromatography with column: 6.1006 .000 anion column super-sep, elluent: $2.5 \mathrm{mmolL}^{-1}$ phathalic acid, $7 \%$ acetonitrile, $\mathrm{pH}=4$ with conductivity detector were used to determine anion concentrations.

\section{Kinetic studies}

Kinetic tests were conducted to study the effect of various parameters on the adsorption efficiency of the anions $\left(\mathrm{NO}_{2}{ }^{-}\right.$and $\mathrm{NO}_{3}{ }^{-}$onto the oxidized carbon sample, RS (ox.). In this respect, $50 \mathrm{mg}$ of adsorbent was shaken with $20 \mathrm{~mL}$ of the solution of an initial concentration of nitrate $50 \mathrm{mg} \mathrm{L}^{-1}$ and $5 \mathrm{mg} \mathrm{L}^{-1}$ of nitrite for different intervals of time. These are the concentration levels of nitrate and nitrite found in various aquaculture and industrial wastewaters [12]. After the required time intervals, the suspension was filtered through a Whatman No. 42 filter paper and analysed for residual anion concentration.

\section{Results and Discussion}

\section{Activated carbon characterization}

The usual way of reporting oxygen content values from elemental analysis is based on the difference between the percentage content of all elements analysed with the residual ascribed to oxygen [13]. RS (ox.) sample, which show a considerable increase in oxygen content (from 0.92 to $5.7 \%$ ) (Table 1 ).

DFT pore size distributions of the adsorbents were studied in Figure 1. The results of surface area and pore volume are given in Table 2. The microporous nature of carbons is demonstrated in Figure 1.

Oxidation enhances pore volume and surface area of the adsorbents without significant changes in the pore size distribution. The surface area and pore volume of oxidized carbon RS(ox.) increased by about 43 and $35 \%$ respectively, compared to those of the unoxidized carbon sample. Oxidized and unoxidized carbon samples possess a significant amount of micropores with a maximum of $1 \mathrm{~nm}$ and mesopores in the range 2-4 $\mathrm{nm}$. The data also show that there was a widening of the pores after the oxidation treatment. There are some enhancement in the microregion and a slight reduction in the mesoporous range (2-4 $\mathrm{nm}$ ). This may be due to a transition from pore width accommodating one adsorbed layer to two, and two layers to three respectively [14].

The fractinal dimensions (D) of two adsorbents are calculated from Frenkel-Halsey-Hill (FHH) models. The unoxidized carbon sample activated at $650^{\circ} \mathrm{C}$ has fraction dimension of $\mathrm{D}=2.1$. This indicates that the surface is very rough or irregular. Upon surface modification using $\mathrm{Na}_{2} \mathrm{CO}_{3}$, the fractal dimension decreases $(\mathrm{D}=2.2)$.

\begin{tabular}{|c|c|c|c|c|c|c|c|}
\hline \multirow{2}{*}{ Sorbent } & \multirow{2}{*}{$\begin{array}{l}\text { Ash } \\
(\%)\end{array}$} & \multirow{2}{*}{$\begin{array}{l}0 \\
\text { (\%) }\end{array}$} & \multicolumn{3}{|c|}{ Elements (wt\%) } & \multirow{2}{*}{$\begin{array}{l}\text { Bulk } \\
\text { density } \\
\left(\mathrm{gmL}^{-1}\right)\end{array}$} & \multirow{2}{*}{$\begin{array}{l}\text { Moisture } \\
\text { Content } \\
(\%)\end{array}$} \\
\hline & & & C & H & $\mathbf{N}$ & & \\
\hline RS (unox.) & 54.0 & 0.92 & 26.0 & 0.94 & - & 0.22 & 18.0 \\
\hline RS (ox.) & 72.8 & 6.57 & 8.97 & 0.46 & - & 0.35 & 12.1 \\
\hline
\end{tabular}

RS (unox.): Unoxidized activated carbon sample; RS (ox.): Oxidized activated carbon sample

Table 1: Physico-chemical characteristics of oxidized and non-oxidized activated carbons.

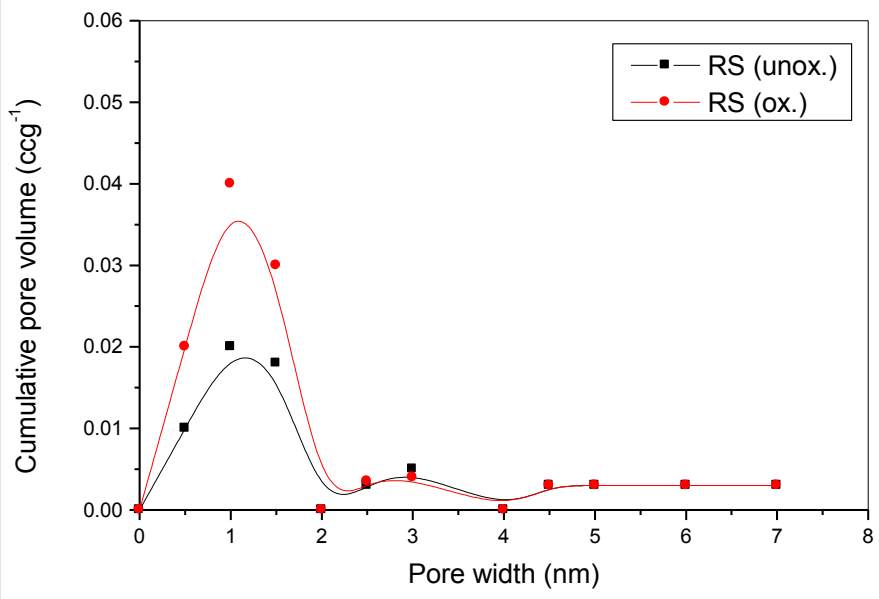

Figure 1: DFT pore size distribution of unoxidized and oxidized rice straw activated carbons. 


\begin{tabular}{|l|l|l|l|}
\hline Sorbent & $\begin{array}{l}\text { DFT Surface area } \\
\left(\mathbf{m}^{\mathbf{2}} \mathbf{g}^{-1}\right)\end{array}$ & $\begin{array}{l}\text { DFT pore volume } \\
\left(\mathbf{c m}^{\mathbf{3}} \mathbf{g}^{-\mathbf{1}}\right)\end{array}$ & $\begin{array}{l}\text { BET surface area } \\
\left(\mathbf{m}^{\mathbf{2}} \mathbf{g}^{-1}\right)\end{array}$ \\
\hline RS (unox.) & 65.3 & 0.064 & 76.2 \\
\hline RS (ox.) & 114.1 & 0.099 & 122.9 \\
\hline
\end{tabular}

RS (unox.): Unoxidized activated carbon sample; RS (ox.): Oxidized activated carbon sample; DFT: Distribution pore size; BET: Surface area characterization of microporous materials

Table 2: Surface area and pore volume of adsorbent materials.

This suggests that the structure of modified carbon became more ordered as the small crystallite and cross-linked structures were partially decomposed. The reactivity of disorganized carbon is greater than that of the crystallite carbon towards such type of reagent; therefore, the carbon in cross-link was mainly consumed. The decomposition of the cross-link leads to the release of plugged pores, which results in an increase of surface area and pore volume, and a decrease of the fractal dimension compared to parent carbon $[15,16]$.

\section{Kinetic studies of anions adsorption}

Effect of agitation time: The time-profile of adsorption of $\mathrm{NO}_{3}{ }^{-}$ and $\mathrm{NO}_{2}^{-}$, onto $\mathrm{RS}$ (ox.) carbon is presented in Figure 2. As agitation time increases, anion removal also increases initially, but then gradually approaches a more or less constant value, denoting attainment of equilibrium. Obviously, equilibrium was attained after shaking for about $10 \mathrm{~h}$ in both cases, beyond which there is no further increase in the adsorption.

Nitrate adsorbed greater than nitrite. This is caused by nitrate have high oxidizing strength. i.e., it is effectively able to extract enough charge from RS (ox.) surface to form sorbed nitrate than in case of nitrite [17].

The kinetic curve of nitrate and nitrite adsorption in Figure 2 indicates that not only the surface of RS (ox.) can adsorb these ions, but also, the inner surface is accessible for ions to diffuse. The former rapid adsorption may be due to the ions adsorbed on the surface of RS (ox.) directly and the latter shows adsorption mainly attributes to long-range diffusion of anions in the inner surface of RS (ox.) where a marginal increase in adsorption is observed up to time after which it is essentially constant.

Kinetic rate parameters: The kinetic experimental data of anions on RS (ox.) sorbent are simulated by the pseudo first-order and pseudo second-order rate equation [18].

$$
\begin{aligned}
& \log \left(\mathrm{q}_{\mathrm{e}}-\mathrm{q}\right)=\log \mathrm{q}_{\mathrm{e}}-(\mathrm{K} 1 / 2.303) \mathrm{t} \quad 1^{\text {st }} \text { order } \\
& \frac{\mathrm{t}}{\mathrm{q}_{\mathrm{t}}}=\frac{1}{\mathrm{k}_{2} \mathrm{q}_{\mathrm{e}}^{2}}+\frac{\mathrm{t}}{\mathrm{q}_{\mathrm{e}}} \quad \ldots \ldots \ldots \ldots \ldots \ldots \ldots \ldots \ldots \ldots \ldots \ldots \ldots \ldots \ldots \ldots \ldots \ldots \ldots \ldots \\
&
\end{aligned}
$$

where $\mathrm{q}_{\mathrm{t}}$ and $\mathrm{q}_{\mathrm{e}}$ are the amount adsorbed $\left(\mathrm{mgg}^{-1}\right)$ at time $\mathrm{t}$ and at equilibrium time respectively and $K_{1}$ and $K_{2}$ are first and second-rate constants of adsorption.

The kinetic experimental data of nitrate and nitrite ions on RS (ox.) are presented in Figure 3 and Table 3.

The correlation coefficient $\mathrm{R}^{2}$ for the pseudo second-order adsorption model has high value for the two anions and the calculated equilibrium adsorption capacities $\mathrm{q}_{\mathrm{e}}$ is consistent with the experimental (Table 3).

Remarkably, the kinetic data of the anions can be described well by the pseudo-second-order rate equation (Table 3 ), the rate-limiting step may be chemical sorption involving valency forces through sharing or exchange of electrons between anions and adsorbent [19].
Table 4 discuss the comparison between adsorption capacities of nitrate and nitrite anions onto various adsorbents and showed that prepared has higher monolayer adsorption capacity than the other ones.

Intra-particle diffusion: The intra-particular diffusion rates $(\mathrm{kp})$ were determined from the plots of $\mathrm{q}_{\mathrm{e}}$ versus $\mathrm{t}^{0.5}$ as shown in Figure 4.

It can be observed that the plots are not linear over the whole time range and reflect a dual nature, with initial linear portion followed by a plateau. This implies the anions are slowly transported via intraparticle diffusion into the particles and is finally retained in the pores. The rate constants of intraparticle diffusion were obtained from the slopes of the straight lines and were found to be 0.62 , and $0.3 \mathrm{mg} \mathrm{g}^{-1}$ $\mathrm{h}^{0.5}$ for nitrate, and nitrite respectively. However, the linear portion of the curves not goes the origin (Figure 4) i.e., the pore diffusion is gets another rate controlling step [20].

\section{Effect of pH}

Figure 5 shows that the effect of $\mathrm{pH}$ on the adsorption of nitrite and nitrate is rather small in case of $\mathrm{NO}_{2}$ anions but amount adsorbed increase gradually at $\mathrm{pH} 8$ in case of nitrate anions. The broad $\mathrm{pH}$ range (3-9) using RS (ox.) carbon makes it a promising adsorbent material to remove nitrate and nitrite from water. Analogous results have

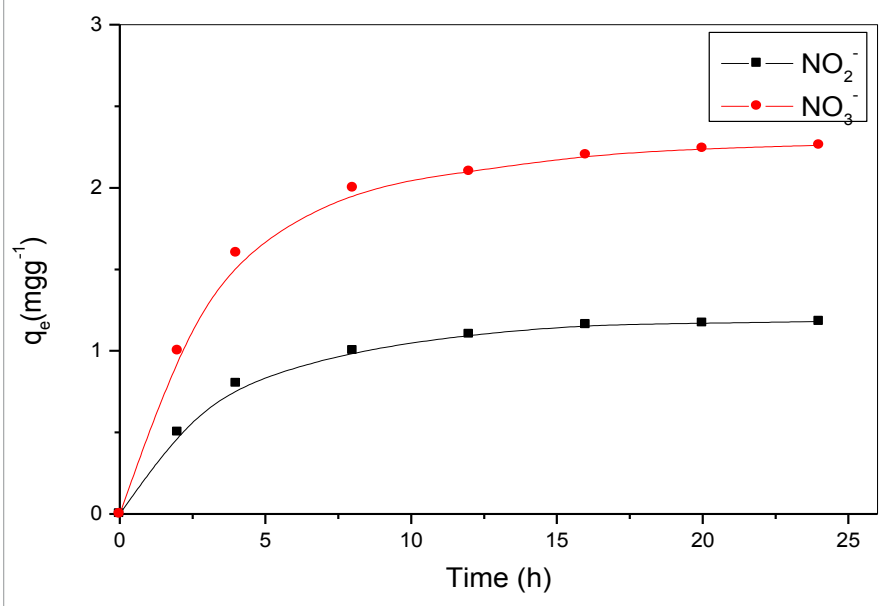

Figure 2: Influence of agitation time on adsorption of $\mathrm{NO}_{3}{ }^{-}$and $\mathrm{NO}_{2}^{-}$by $\mathrm{RS}$ (ox.).

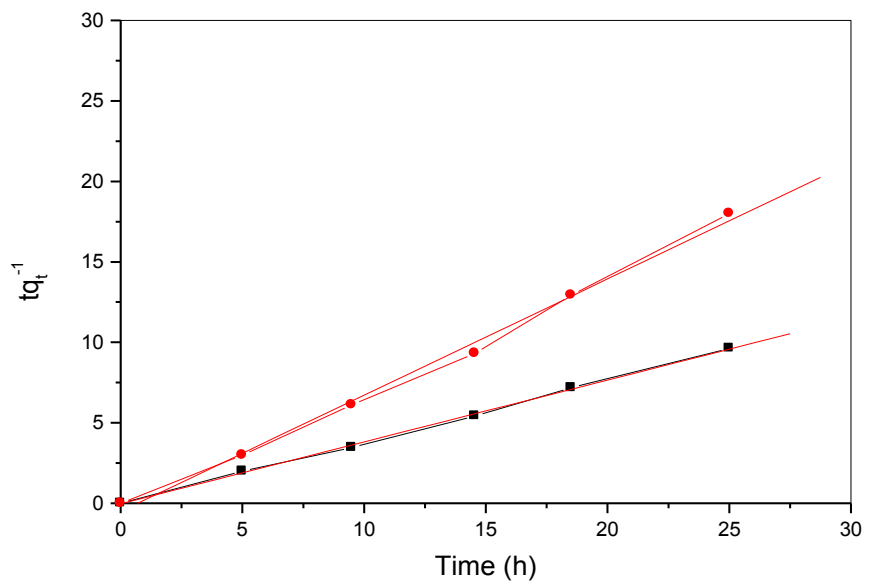

Figure 3: Pseudo-second-order sorption kinetics of $\mathrm{NO}_{3}^{-}$and $\mathrm{NO}_{2}^{-}$. 
Citation: Hanafi HA, Azeema SMA (2016) Removal of Nitrate and Nitrite Anions from Wastewater Using Activated Carbon Derived from Rice Straw. J Environ Anal Toxicol 6: 346. doi:10.4172/2161-0525.1000346

Page 4 of 6

\begin{tabular}{|l|l|l|l|}
\hline Model & Parameter & NO3- & NO2- \\
\hline \multirow{5}{*}{ First-order model } & qe, $\left(\mathrm{mg} \mathrm{g}^{-1}\right)$ & 2.1 & 1.1 \\
\hline \multirow{5}{*}{ Second-order model } & $\mathrm{K}_{1}(\mathrm{~h}-1)$ & 0.12 & 0.06 \\
\cline { 2 - 4 } & $\mathrm{qe}, \mathrm{cal}\left(\mathrm{mg} \mathrm{g}^{-1}\right)$ & 0.2 & 0.4 \\
\hline & $\mathrm{R}^{2}$ & 0.945 & 0.62 \\
\hline & $\mathrm{K}_{\mathbf{2}}\left(\mathbf{g m g}^{-1} \mathbf{~}^{-1}\right)$ & 0.17 & 0.3 \\
\cline { 2 - 4 }$\left(\mathrm{mg} \mathrm{g}^{-1} \mathbf{h}\right)$ & 1.34 & 0.4 \\
\hline & $\mathrm{qe}, \mathrm{cal}\left(\mathrm{mg} \mathrm{g}^{-1}\right)$ & 2.19 & 1.12 \\
\hline & $\mathrm{R}^{2}$ & 0.94 & 0.92 \\
\hline
\end{tabular}

NO3-: Nitrate anion; NO2-: Nitrite anion

Table 3: Comparison of the pseudo first/second-order adsorption rates constants and the calculated/experimental qe values for $\mathrm{NO}_{3}$ - and $\mathrm{NO}_{2}-$

\begin{tabular}{|l|l|l|}
\hline Adsorbent & qo (mg/g) & Ref. \\
\hline $\mathrm{RS}_{2} / \mathrm{Na}_{2} \mathrm{CO}_{3}$ & 8.2 & This work \\
\hline Bamboo powder charcoal & 1.25 & {$[29]$} \\
\hline Commercial activated carbon & 1.09 & {$[29]$} \\
\hline M. oleifera hull (anion exchanger) & 11.78 & {$[30]$} \\
\hline Lauan sawdust (anion exchanger) & 8.68 & {$[30]$} \\
\hline Coconut husk & 7.44 & {$[30]$} \\
\hline Persimmon tealeaf (anion exchanger) & 5.58 & {$[30]$} \\
\hline Pine bark (anion exchanger) & 4.34 & {$[30]$} \\
\hline Rice hull (anion exchanger) & 6.2 & {$[30]$} \\
\hline Sugarcane bagasse (anion exchanger) & 3.72 & {$[30]$} \\
\hline Chinese tealeaf (anion exchanger) & 2.48 & {$[30]$} \\
\hline Surfactant-modified zeolite (100\% HDTMA loading) & 3.97 & {$[30]$} \\
\hline Surfactant-modified zeolite (150\% HDTMA loading) & 6.63 & {$[30]$} \\
\hline Surfactant-modified zeolite (200\% HDTMA loading) & 5.64 & {$[30]$} \\
\hline
\end{tabular}

Table 4: Comparison of the maximum monolayer adsorption capacities of nitrate anion on various adsorbents.

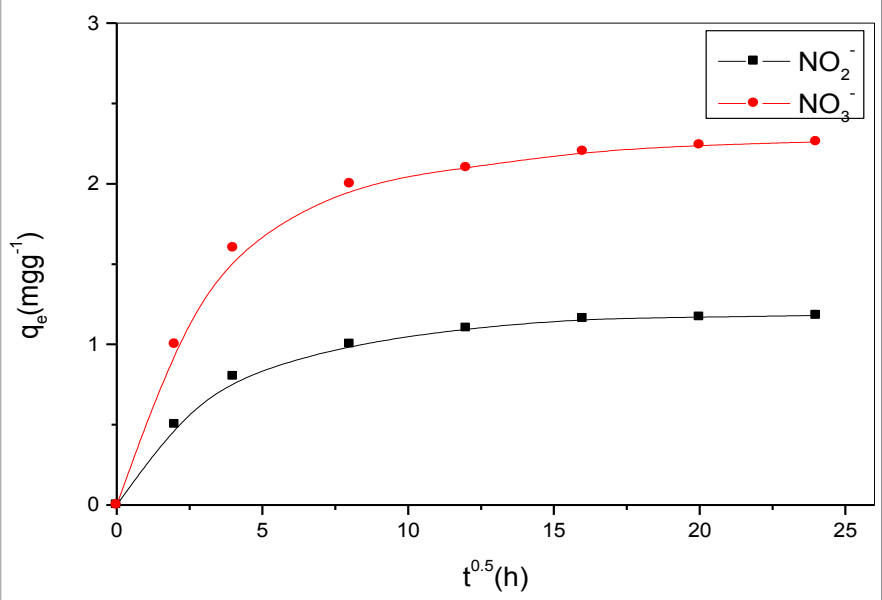

Figure 4: Intra-particle diffusion plot for nitrate and nitrite adsorption onto RS (ox.) Carbon.

been reported for the removal of nitrate on palladium-based catalysts supported on activated carbons [21,22], nitrate by sepiolite [23], nitrate by modified amine coconut coir [12], and nitrate and nitrite on ion exchangers [24].

Possible working mechanisms: The adsorption sites in active carbons can be divided into two major types; these are

(i) Hydrophobic surfaces comprising of the graphene layers; and (ii) oxygen functional groups which are primarily hydrophilic. This provides two main possibilities for nitrate and nitrite adsorption (a)

adsorption by interaction between the p orbitals of the graphene layers and anions; or (b) an ion exchange mechanism involving the functional groups [25].

The $\mathrm{pH}$ of the medium would definitely influence the course of the $2^{\text {nd }}$ mechanism, but the $1^{\text {st }}$ mechanism may operate over a large range of $\mathrm{pH}$ without being affected much. The amount of nitrate and nitrite adsorbed in the present work remained nearly constant in the $\mathrm{pH}$ range of 2.0-10.0 (Figure 6), and therefore, the adsorption of $\mathrm{NO}_{3}^{-}$and $\mathrm{NO}_{2}^{-}$ on RS (ox.) is expected to occur between the delocalised $\pi$-electrons of the oxygen free Lewis basic sites and the free electrons of the anions $(\pi-\pi$ argument).

\section{Thermodynamic Studies for $\mathrm{NO}_{3}$ anions}

Temperature effect: The isotherm constants for the sorption of $\mathrm{NO}_{3}{ }^{-}$ions onto RS (ox.) carbon by the three models: Freundlich (F), Langmuir (L), and Langmuir-Freundlich (LF) at different temperatures are presented in Table 5 .

Based on the correlation coefficient values, $\mathrm{R}^{2}$, generally, $\mathrm{LF}$ isotherm still found to be a good representative for the experimental data over the whole concentration range with high correlation coefficient values.

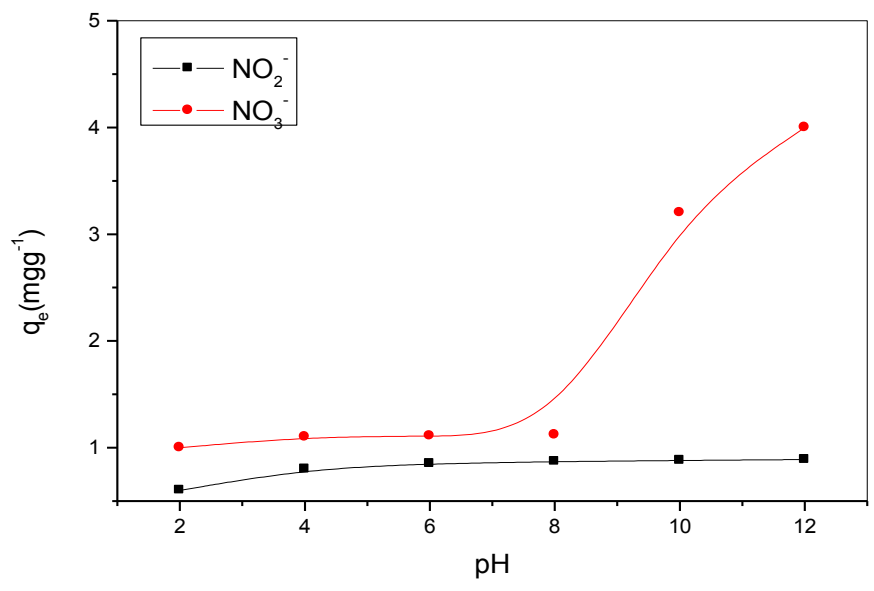

Figure 5: Effect of $\mathrm{pH}$ on the adsorption of nitrate and nitrite by $\mathrm{RS}$ (ox.) Carbon.

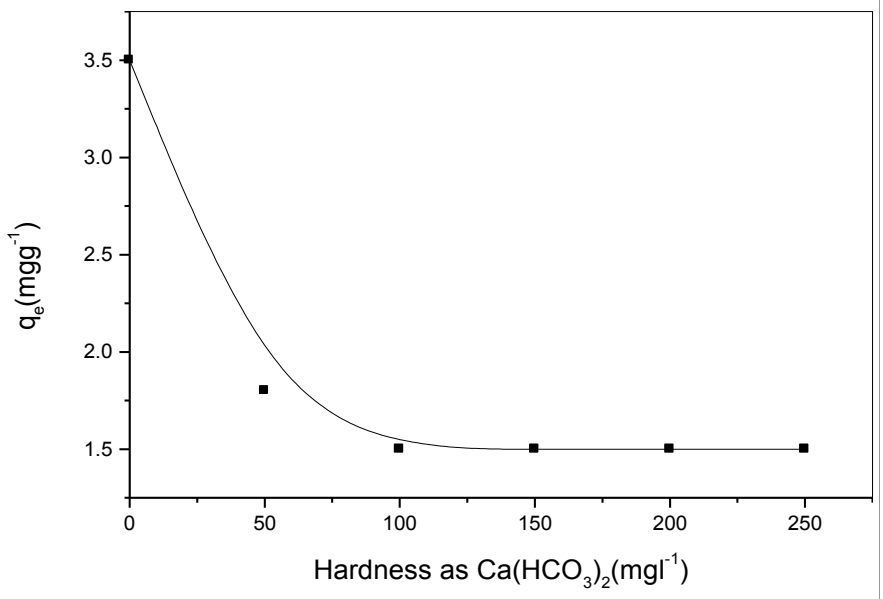

Figure 6: Effect of hardness on nitrate removal using RS (ox.) Carbon. 
The $\mathrm{q}^{\circ}$ values calculated from LF model were found to decrease by increasing temperature. This is referred to the solubility of the adsorbate. The solubility of $\mathrm{KNO}_{3}$ increases from $31.6 \mathrm{~g}$ per $100 \mathrm{~g}$ water at $20^{\circ} \mathrm{C}$ to $110 \mathrm{~g}$ per $100 \mathrm{~g}$ water at $60^{\circ} \mathrm{C}$.

An alternative hypothesis would be due to an increase of temperature causes a shift of the point of zero charge (pzc) of carbon to low $\mathrm{pH}$ values and the surface charge density at a given $\mathrm{pH}$ becomes more negative. This creates unfavorable conditions for adsorption of anions [26].

Thermodynamic parameters: The value of enthalpy change $\left(\Delta \mathrm{H}^{\circ}\right)$ and entropy change $\left(\Delta S^{\circ}\right)$ were obtained in Table 6.

The thermodynamic equilibrium constant $\mathrm{K}_{\mathrm{o}}$ equal to $\mathrm{q}^{\mathrm{o}^{*}} \mathrm{~b}$ of LF isotherm. The thermodynamic parameters determined for the adsorption of $\mathrm{NO}_{3}{ }^{-}$onto $\mathrm{RS}$ (ox.) carbon is given in Table 6 using the following thermodynamic equations [27]:

$$
\begin{aligned}
\ln \mathrm{k}_{\mathrm{o}} & =\frac{\Delta \mathrm{S}^{\mathrm{o}}}{\mathrm{R}}-\frac{\Delta \mathrm{H}^{\mathrm{o}}}{\mathrm{RT}} \\
\Delta \mathrm{G}^{\mathrm{o}} & =-\mathrm{RT} \ln \mathrm{k}_{\mathrm{o}}
\end{aligned}
$$

where $\Delta \mathrm{G}^{\circ}$ is the standard free energy, $\mathrm{R}=$ Universal gas constant (1.987 $\mathrm{calmol}^{-1} \mathrm{~K}^{-1}$ or $8.314 \mathrm{jmol}^{-1} \mathrm{~K}^{-1}$ ) and $\mathrm{T}=$ Absolute temperature in kelvin (K).

The exothermic nature of adsorption is indicated by the negative value of $\Delta \mathrm{H}^{\circ}$. The entropy $\left(\Delta \mathrm{S}^{\circ}\right)$ value suggests no significant change occurs in the internal structure of RS (ox.) carbon during the adsorption [28]. The sorption process takes place with an increase in the order of the system. The positive value of $\Delta \mathrm{G}^{\circ}$ indicates the formation of thermodynamically unstable adsorbed species. This positive value of $\Delta \mathrm{G}^{\circ}$ indicates that better adsorption, is obtained at a lower temperature.

\section{Effect of hardness on nitrate removal}

The co-existing ions selected were calcium hydrogen carbonate that is typically found in ground water and cause temporary hardness. It is demonstrated in Figure 6. The nitrate removal is appreciably decreased in the presence of $\mathrm{Ca}\left(\mathrm{HCO}_{3}\right)_{2}$. The inhibiting effect of these species can be ascribed to the identical structures of $\mathrm{NO}_{3}{ }^{-}$and $\mathrm{HCO}_{3}{ }^{-}$ions. They are both planar, and the angles between the $\mathrm{N}-\mathrm{O}$ and $\mathrm{C}-\mathrm{O}$ bonds are identical and equal to $120^{\circ} \mathrm{C}$. It can be thus reasonably believed that $\mathrm{HCO}_{3}{ }^{-}$anions competitively adsorb to the same active sites on the surface of the RS (ox.) carbon $[29,30]$.

These results indicate that $\mathrm{KMnO}_{4}$ modified activated carbon produced from rice straw is much better or even superior than any of these sorbents. This is probably related to the sorption mechanism which including both ion exchange and complexation.

\section{Conclusion}

Indeed, one of the methods for decreasing the large volumes of waste and toxic effluents produced by a variety of chemical processes is the development of low-cost adsorbents, which is one of the major goals of green chemistry. In this sense, the steam activated carbon derived from rice straw and modified by potassium permanganate showed good adsorption ability for nitrate and nitrite ins from aqueous solutions. In this concern, Factors affecting the removal of nitrate and nitrite ions in single-component systems were investigated: temperature, $\mathrm{pH}$, adsorbent concentration and carbon dosages. In the binary system $\left(\mathrm{NO}_{3}\right.$ and $\left.\mathrm{HCO}_{3}\right)$, the inhibitive effect of hardness on nitrate removal is referred to the identical structure of $\mathrm{NO}_{3}$ and $\mathrm{HCO}_{3}$ ions and in the

\begin{tabular}{|c|c|c|c|c|c|c|c|c|c|c|c|}
\hline \multirow{2}{*}{ Anion } & \multirow{2}{*}{$\begin{array}{l}\text { Temp. } \\
{ }^{\circ} \mathrm{C}\end{array}$} & \multicolumn{3}{|c|}{ Frundlich } & \multicolumn{3}{|c|}{ Langmuir } & \multicolumn{4}{|c|}{ Langmuir-Freundlich } \\
\hline & & $\mathbf{K}$ & n & $\mathbf{R}^{2}$ & qo & b & $\mathbf{R}^{2}$ & qo & b & n & $\mathbf{R}^{2}$ \\
\hline \multirow{3}{*}{ NO3- } & 25 & 0.12 & 0.92 & 0.75 & 17.7 & 0.01 & 0.66 & 3.3 & 0.03 & 0.11 & 0.990 \\
\hline & 45 & 0.08 & 0.82 & 0.66 & 15.6 & 0.01 & 0.4 & 2.5 & 0.04 & 0.06 & 0.993 \\
\hline & 55 & 0.03 & 0.6 & 0.7 & 12.6 & 0.01 & 0.62 & 2.2 & 0.03 & 0.05 & 0.999 \\
\hline
\end{tabular}
system $\left(\mathrm{NO}_{3}\right.$ and $\left.\mathrm{NO}_{2}\right)$, the nitrate sorption was suppressed due to the
K: Freundlich constant; $\mathrm{q}^{0}$ : The amount of solute adsorbed at equilibrium per unit; $\mathrm{n}$ : Freundlich constant weight of adsorbent required for monolayer of the surface; $\mathrm{R}^{2}$ : Correlation coefficient values $\mathrm{b}$ constant related to the heat of adsorption

Table 5: Characteristic parameters of the experimental data according to the Langmuir, Freundlich and Langmuir-Freundlich equations for the adsorption of

\begin{tabular}{|c|c|c|c|c|c|c|c|c|}
\hline \multirow{2}{*}{ Anion } & \multicolumn{3}{|c|}{ ko $\left(\mathrm{L} \mathrm{g}^{-1}\right)$} & \multirow[t]{2}{*}{$\begin{array}{l}\Delta \mathrm{Ho} \\
\left(\mathrm{kJmol}^{-1}\right)\end{array}$} & \multirow[t]{2}{*}{$\begin{array}{l}\Delta \text { So } \\
\left(\mathrm{J} \mathrm{mol}^{-1} \mathrm{~K}^{-1}\right)\end{array}$} & \multicolumn{3}{|c|}{$\Delta \mathrm{Go}\left(\mathrm{KJmol}^{-1}\right)$} \\
\hline & 298K & $318 K$ & $328 \mathrm{~K}$ & & & 298K & 318K & $328 \mathrm{~K}$ \\
\hline NO3- & 0.33 & 0.25 & 0.2 & -12.8 & -0.76 & 2.8 & 3.7 & 4.4 \\
\hline
\end{tabular}
NO3- onto RS (ox.).

$\mathrm{k}_{0}$ : Thermodynamic equilibrium constant; $\Delta \mathrm{Ho}$ : Enthalpy change; $\Delta$ So: Entropy change; $\Delta \mathrm{Go}$ : The standard free energy

Table 6: Thermodynamic parameters of $\mathrm{NO}_{3}$ - sorption on to $\mathrm{RS}$ (ox.) carbon.

competitive effect whereas the nitrite sorption was promoted due to the cooperative adsorption. In presence or absence of NOM, the adsorptive capacity was similar, indicating that the affinity of nitrate for the carbon surface is stronger than the attraction between nitrate and NOM.

\section{Acknowledgements}

Many thanks to my friends in hot laboratories centre- Egyptian atomic energy authority to help me in this research, also I want to thank all members in centra laboratory in college of science and humanities- Shaqra University for their great efforts in this research.

\section{References}

1. Katta JR, Jianping $L(2000)$ Nitrate removal from groundwater using catalytic reduction. Wat Res 34: 995-1001

2. Hallberg GR (1987) Agricultural chemicals in ground water: Extent and implications. Am J Alternative Agric 2: 3-15.

3. Pinar G, Duque E, Haidour A, Oliva J, Sanchez-Barbero L, et al. (1997) Removal of High Concentrations of Nitrate from Industrial Wastewaters by Bacteria. Appl Environ Microbiol 63: 2071-2073.

4. Canter LW (1996) Nitrates in Ground water. CRC Press, Boca Raton, FL, USA

5. Deganello F, Liotta LF, Macaluso A, Venezia AM, Deganello G (2000) Catalytic reduction of nitrates and nitrites in water solution on pumice-supported $\mathrm{Pd}-\mathrm{Cu}$ catalysts. Appl Catal B: Environmental 24: 265-273.

6. Glass C, Silverstein J (1998) Denitrification kinetics of high nitrate concentration water: $\mathrm{pH}$ effect on inhibition and nitrite accumulation. Wat Res 32: 831-839.

7. Aslan S, Türkman A (2004) Simultaneous biological removal of endosulfan $(\alpha+\beta)$ and nitrates from drinking waters using wheat straw as substrate. Environ Intern 30: 449-455

8. Daifullah AAM (2003) Isotope and Radiation Research 35: 77.

9. Mckay G (1996) Use of adsorbent for the removal of pollutants from wastewater CRC press, NY, USA.

10. Leon Y, Leon CA, Solar JM, Calemma V (1992) Evidence for the protonation of basal plane sites on carbon. Carbon 30: 797-811.

11. Bandosz TJ, Jagiello J, Schwarz JA (1992) Comparison of methods to assess surface acidic groups on activated carbons. ACS 64: 891-895.

12. Lin SH, Wu CL (1997) J Environ Sci Health A32: 1575.

13. Salame II, Bandosz TJ (2001) Surface Chemistry of Activated Carbons: Combining the Results of Temperature-Programmed Desorption, Boehm and Potentiometric Titrations. J Colloid Interface Sci 240: 252-258.

14. Villar-Rodile S, Denoyel R, Rouquerol J, Martinez-Alonso A, Tascon JMD (2002) Porous Texture Evolution in Nomex-Derived Activated Carbon Fibers. J Colloid Interface Sci 252: 169-179. 
Citation: Hanafi HA, Azeema SMA (2016) Removal of Nitrate and Nitrite Anions from Wastewater Using Activated Carbon Derived from Rice Straw. J Environ Anal Toxicol 6: 346. doi:10.4172/2161-0525.1000346

15. Pyun SI, Rhee CK (2004) An investigation of fractal characteristics of mesoporous carbon electrodes with various pore structures. Electrochim Acta 49: $4171-4180$

16. Hayashi J, Horikawa T, Muroyama K, Gomes VG (2002) Activated carbon from chickpea husk by chemical activation with $\mathrm{K} 2 \mathrm{CO} 3$ : preparation and characterization. Microporous Mesoporous Mater 55: 63-68.

17. Miletic M, Gland JL, Hass KC, Schneider WF (2003) Characterization of adsorption trends of NO2, nitrite, and nitrate on MgO terraces. Surf Sci 546 75-86.

18. Ho YS, McKay G (2000) The kinetics of sorption of divalent metal ions onto sphagnum moss peat. Wat Res 34: 735-742.

19. Gücek A, Sener S, Bilgen S, Mazmanc MA (2005) Adsorption and kinetic studies of cationic and anionic dyes on pyrophyllite from aqueous solutions. J Colloid Interface Sci 286: 53-60.

20. Cox M, Pichugin AA, El-Shafey EI (2005) Sorption of precious metals onto chemically prepared carbon from flax shive. Hydrometallurgy 78: 137-144.

21. Lemaignen L, Tong C, Begon V, Burch R, Chadwick D (2002) Catalytic denitrification of water with palladium-based catalysts supported on activated carbons. Catal Today 75: 43-48

22. Öztürk N, Bektas TE (2004) Nitrate removal from aqueous solution by adsorption onto various materials. J Hazard Mater 112: 155-162.
23. Baes AU, Okuda T, Nishijima W, Shoto E, Okada M (1997) Adsorption and ion exchange of some groundwater anion contaminants in an amine modified coconut coir. Wat Sci Tech 35: 89-95.

24. Jia YF, Steele CJ, Hayward IP, Thomas KM (1998) Mechanism of adsorption of gold and silver species on activated carbons. Carbon 36: 1299-1308.

25. Giles CH, MacEwan TH, Nakhawa SN, Smith A (1960) Studies in adsorption. Part XI. A system of classification of solution adsorption isotherms, and its use in diagnosis of adsorption mechanisms and in measurement of specific surface areas of solids. J Chem Soc 111: 3973-3993.

26. Hunt JA, Sykes A (1987) Chemistry. Longman Group, Hong Kong.

27. Sekar M, Sakthi V, Rengaraj S (2004) Kinetics and equilibrium adsorption study of lead(II) onto activated carbon prepared from coconut shell. J Colloid Interface Sci 279: 307-313.

28. Gupta VK, Mittal A, Gajbe V (2005) Adsorption and desorption studies of a water soluble dye, Quinoline Yellow, using waste materials. J Colloid Interface Sci 284: 89-98.

29. Alam JB, Dikshit AK, Bandyopadhayay M (2005) Evaluation of thermodynamic properties of sorption of 2,4-D and atrazine by tire rubber granules. Sep Purif Technol 42: 85-90.

30. Pintar A, Setinc M, Levec J (1998) Hardness and Salt Effects on Catalytic Hydrogenation of Aqueous Nitrate Solutions. J Catal 174: 72-87. 